\title{
LA ESPECIALIDAD DEL PROCESO PENAL JUVENIL Y EL PROCEDIMIENTO ABREVIADO*
}

\author{
Specialty juvenile criminal proceedings and summary proceedings
}

Leonardo Leiva Mendoza**

\begin{abstract}
Resumen: El presente trabajo examina las relaciones entre el principio de especialidad establecido en proceso penal adolescente y la procedencia del procedimiento abreviado dispuesto en el Código Procesal Penal de aplicación a los adultos. El análisis aborda tres aspectos principales. Primero, una valoración general sobre los argumentos a favor y en contra de la procedencia del procedimiento abreviado atendidos los principios que orientan y limitan el sistema penal adolescente. Segundo, una propuesta de concreción del principio de especialidad al tema en estudio. Y por último un examen de las competencias y capacidades de los adolescentes para actuar en juicio, y las exigencias que de estas se derivan para la renuncia de derechos y el ejercicio de la defensa jurídica.
\end{abstract}

Palabras clave: procedimiento abreviado, proceso penal de adolescentes, principio de especialidad, justicia juvenil, adolescentes infractores.

Abstract: This paper examines the relations between the principle of specialty stablished in the criminal procedure of juvenile offenders and the plea bargain regulated in the code of criminal procedure for adults. The analysis approaches three mains aspects. First, it develops a general assessment about the arguments in favor and against the properness of the plea bargain considering the guidelines and principles that limit the juvenile criminal system. Second, a concretion proposal of the principle of specialty at the topic under study. And finally an examination of the competences and capacities of youth required to stand in trial, and the requirements derivatived from them to the waiver of rights and exercise the right of defence.

Keywords: plea bargain, criminal procedure of juvenile offenders, principle of specialty, juvenile justice, young offenders.

\section{"In assuming that children's due process rights would, at best, match those of adults, the Court foreclosed any consideration of the changes required to make the juvenile justice system fair to children"}

Emily Buss, sobre In re Gault

\footnotetext{
* El artículo tiene su origen en una tesina presentada para el Magister en Derecho Penal y Procesal Penal de la Universidad Diego Portales.

** Abogado, Universidad Diego Portales. Diplomado en Gerencia Social y Políticas Públicas, FLACSO-Chile. Magister en Derecho Penal y Procesal Penal, Universidad Diego Portales. Asesor Legislativo Secretaría Ejecutiva Consejo Nacional de la Infancia, Ministerio Secretaría General de la Presidencia. Correo electrónico: leonardoleivam@gmail.com
}

Este artículo fue recibido el 5 de julio de 2016, siendo aprobada su publicación el 25 de octubre de 2016. 


\section{Introducción}

Desde la entrada en vigencia de la Ley 20.084 (en adelante LRPA) se ha discutido si resulta procedente la aplicación del procedimiento abreviado, regulado en el Código Procesal Penal, al ámbito de la justicia penal juvenil. El motivo de esta discusión se debe a que la LRPA no hizo referencia alguna al procedimiento abreviado tratándose de adolescentes. Por ende, esta especie de laguna o vacío jurídico ha debido ser completado por el quehacer del sistema de justicia criminal, principalmente por la jurisprudencia, que se ha manifestado heterogéneamente tanto a favor como en contra de su aplicación. En ambos casos, concentrando el debate en aspectos, a nuestro parecer superficiales del problema, como el alcance del carácter supletorio del CPP en relación a la LRPA o si este debiese permitirse únicamente si la pena solicitada por el Ministerio Público no trae aparejada una sanción privativa de libertad. ${ }^{1}$

En el contexto señalado el propósito de este trabajo es entrar al debate de la procedencia del procedimiento abreviado en el ámbito de la justicia penal juvenil desde un ámbito más bien valorativo, es decir, se trata de problematizar acerca de la existencia de mecanismos como el procedimiento abreviado en la justicia juvenil. En un sentido negativo, el presente trabajo no tiene por objetivo directo responder si de acuerdo al estado actual de las normas vigentes (CPP y LRPA) la respuesta debiese ir en un sentido u otro. Esto no obsta, por cierto, a que de acuerdo a los aspectos que se desarrollan exista un pronunciamiento al respecto.

La mejor herramienta para dar con el objetivo de problematizar en torno al procedimiento abreviado en la justicia juvenil está dada por el desarrollo de los Derechos de los Niños y toda la doctrina que respecto de ellos se ha construido (en el contexto del sistema penal). A nuestro entender es el principal elemento del que ha carecido hasta ahora el debate. Ahora bien, esta forma de aproximación al problema no está exenta de las dificultades propias de un campo que para el Derecho es sumamente fértil y en el que existe poco desarrollo aún en nuestra cultura jurídica sobre cómo deben ser entendidos una serie de aspectos que los Derechos de los Niños ponen de relieve. Por este motivo, junto con abordar el objetivo principal del trabajo se propenderá a ir delimitando como deben ser entendidos algunos aspectos concretos relativos a los derechos de los niños.

Conforme a lo anterior, cabe precisar dos aspectos en relación a las fuentes de información. Primero, intencionalmente se ha decidido trabajar con fuentes bibliográficas en el entendido que la jurisprudencia emanada de nuestro sistema no permite abordar en profundidad el debate y, por lo mismo, no permite salir de los deslindes que ha fijado. Y segundo, en el tratamiento de los problemas

\footnotetext{
${ }^{1}$ Una síntesis de este debate puede encontrarse en la justificación del Boletín 8906-07 del Senado, patrocinado por la Senadora Sra. Lily Pérez, el que tiene por objetivo zanjar el debate legislando a favor de la procedencia del abreviado, permitiéndolo inclusive para aquellos casos en que el Ministerio Público solicita una pena privativa de libertad.
} 
identificados, así como en las argumentaciones en torno a ellos se ha preferido excluir en la medida de lo posible toda aquella información que no tenga un carácter estrictamente jurídico. Esto se debe a que, especialmente a nivel comparado, el estudio de mecanismos como el procedimiento abreviado suele ser objeto de otras disciplinas que con mayor certeza y metodología que la jurídica pretenden abordar el real comportamiento de este tipo de instituciones legales. Sin duda, esto enriquece el debate pero excede el objetivo de este trabajo. De este modo, el trabajo será realizado íntegramente en base a bibliografía jurídica penal y procesal penal y de los derechos de los niños.

En cuanto al tratamiento del problema, el camino elegido es desde el mandato de especialidad, ${ }^{2}$ profundizar en su sustrato. Y no abordarlo metodológicamente desde los problemas generales que una institución como el procedimiento abreviado presenta en su aplicación ${ }^{3}$ o a través de la búsqueda de una simetría [lógica] entre derecho penal y procesal penal. ${ }^{4}$ No implica esto, por cierto, que determinados problemas que presenta esta institución no puedan ser empleados para ejemplificar y reforzar su cercanía o lejanía con la especialidad del proceso penal juvenil. ${ }^{5}$

La estructura del trabajo consta de cuatro secciones y, acto seguido, se expresan algunas conclusiones finales.

La primera sección (1) corresponde a un aspecto central -y que es previo al debate específico sobre el procedimiento abreviado en la justicia penal juvenil-, la noción de especialidad o principio de especialidad en materia procesal. En este punto, se trata de delimitar de qué forma debe entenderse la especialidad, su mandato específico y alcances.

Luego, la sección segunda (2) obedece a dos propósitos. En primer término, describe los principales aspectos del procedimiento abreviado que para efectos del objetivo del trabajo importan. $\mathrm{Y}$ en segundo término, expone los principales cuestionamientos -jurídicos- que a nivel general presentan los mecanismos como el procedimiento abreviado y desarrolla los problemas específicos que se han detectado a la regulación del CPP.

\footnotetext{
${ }^{2}$ Para una aproximación al problema que concibe al principio de especialidad como un eje, véase: Beloff, et al (2015: 1-8).

${ }^{3}$ Este es uno de los caminos habitualmente seguidos para rechazar este tipo de mecanismos especialmente en sistemas de enjuiciamiento que han evidenciado el comportamiento real de estos, principalmente a través de estudios empíricos de énfasis sociológico que permiten construir argumentos político criminales en torno a su no deseabilidad.

${ }^{4}$ Lo que pudiese ser aún más complejo dada la falta de uniformidad existente en el ámbito penal sustantivo en lo que se refiere al alcance de la especialidad. En este sentido, véase: Maldonado (2014: 18-19). Una aproximación que sigue este camino de manera estricta puede apreciarse en: Sala (2002: 61-67).

5 El punto es evitar caer en consideraciones más criminológicas o sociológicas sobre el funcionamiento de este tipo de instituciones.
} 
Posteriormente, el desarrollo de las secciones tercera y cuarta está estrechamente ligado. En la tercera sección (3), se abordan dos problemas que aun cuando podrían estimarse como problemas generales dentro del debate acerca de la justicia penal juvenil, cobran especial relevancia tratándose de la procedencia del procedimiento abreviado. Estos son, por una parte, las competencias y capacidades de los adolescentes y, por otra, la necesidad de diferencias en el proceso penal aplicable a los adolescentes. En esta sección se presenta una postura respecto a la improcedencia del procedimiento abreviado en la justicia penal juvenil.

En la cuarta sección (4), se aborda la procedencia e improcedencia del abreviado en el escenario en que actualmente la doctrina ha situado el debate, es decir en relación a los estándares de renuncia de derechos y el rol de los abogados defensores. Dicho de otra forma, se analiza si acaso estos aspectos (como han sido concebidos) permiten cambiar la postura asumida en el capítulo tercero respecto a la improcedencia del abreviado. En concreto, si permiten superar los problemas de competencias y capacidades de los adolescentes y/o la necesidad de mayores diferencias entre el proceso penal de adolescentes y el de adultos. De esta forma, se permite reforzar la postura planteada en la sección tercera. Luego, al término de esta sección, se plantean algunas ideas generales que pudiesen orientar una modificación legal en la materia. Por último, se exponen algunas conclusiones generales sobre los diversos aspectos abordados en el trabajo.

\section{Ley 20.084 y Código Procesal Penal: especialidad del proceso penal juvenil}

\subsection{Entrada en vigencia de la LRPA y la promesa de especialidad procesal}

Luego de quince años de ratificada la Convención sobre los Derechos del Niño (en adelante CDN), con la entrada en vigencia de la Ley 20.084, el Estado de Chile cumplió parte del compromiso asumido de adecuar su normativa interna a uno de los diversos aspectos abordados en el tratado. En concreto, se decidió reformar uno de los pilares más fuertes de la vigencia del sistema tutelar de menores en el país -sistema que a la fecha aún conserva serios resabios de permanencia en el ámbito institucional y proteccional-. Precisamente, es la ratificación de la $\mathrm{CDN}$ y el nuevo contexto político democrático lo que da pie a un importante proceso técnico de análisis y discusión sobre el sistema de "menores" vigente en el país en ese entonces. Los primeros esfuerzos y propuestas por modificar el sistema vigente se sitúan a principios de los años '90, con orientaciones un poco imprecisas en un comienzo, no obstante, al poco tiempo encauzan una orientación clara y consistente con la CDN. ${ }^{6}$

${ }^{6}$ Para conocer en detalle la evolución del proceso que culmina con la Ley 20.084, véase: De Ferari (2006: 113-158). 
En lo que es pertinente a este trabajo, y aun cuando pueda parecer obvio, los diversos esfuerzos por discutir un sistema de justicia penal juvenil consistente con la $\mathrm{CDN}$, no siempre tuvieron como horizonte técnico-político el nuevo sistema de enjuiciamiento penal instalado por la reforma procesal penal. De hecho, si bien la génesis de esta reforma también se ubica a principios de los años '90, con importantes esfuerzos políticos, técnicos y académicos, no es claro que ambos procesos durante toda su génesis hayan "conversado". Ahora, lo que si se evidenció fue la peor posición en que se encontraban los adolescentes frente al sistema penal con la reforma procesal penal vigente. Sin ir más lejos, expresamente el Mensaje Presidencial No $68-347$ de $2002^{7}$-que da origen a la Ley 20.084- se encarga de indicar que como consecuencia del perfeccionamiento de la justicia penal de adultos, ahora la posición jurídica de los adolescentes se ha visto aún más desmedrada. ${ }^{8}$ Este antecedente, que en principio pudiese parecer algo de una relevancia mínima, veremos más adelante que no es un hecho menos significativo, especialmente en lo que dice relación con la búsqueda del contenido de la "especialidad" del proceso penal juvenil.

El Mensaje referido, igualmente señalaba "siguiendo la más moderna doctrina, el Proyecto recepciona todas las garantías penal y procesales propias de los adultos, agregando garantías específicas para los adolescentes", continúa dos párrafos más adelante "En el ámbito procesal se recogen los principios fundamentales del nuevo Código Procesal Penal, estructurándose un procedimiento acusatorio oral...". " Es importante destacar la coherencia de la semántica del mensaje previo al articulado con el desarrollo normativo efectivamente realizado. El Título III (artículos 34 al 64), denominado del "Procedimiento", ${ }^{10}$ contemplaba 30 artículos donde se pretendía dar forma a un sistema de enjuiciamiento que pudiese comportarse de manera distinta -en relación al sistema general o de adultos- frente a los adolescentes. Aspecto que desde el punto de vista formal poseía gran significancia, no obstante desde el punto de vista técnico recibía la crítica de haber cambiado su orientación respecto de los proyectos que se habían trabajado con anterioridad (Duce, 2003: 101).

En el curso del debate legislativo, en ambos trámites constitucionales, el proyecto sufrió bastantes transformaciones. Lo relativo al ámbito procesal no fue la excepción, y de la propuesta de 30 artículos -ya cuestionados técnicamente- que

\footnotetext{
${ }^{7}$ A la fecha de presentación del Mensaje, se encontraban vigentes todas las normas que hacían operativa la reforma procesal penal, inclusive esta se encontraba en su segunda etapa de implementación gradual en el territorio nacional.

${ }^{8}$ El Mensaje señala: "Se da la inconsecuencia que el sistema especial de menores, nacido para proteger los derechos de los niños, ha terminado por desmedrar su posición jurídica, situación que se ha hecho aún más evidente a partir del perfeccionamiento de la justicia penal de adultos con la entrada en vigencia del nuevo sistema de enjuiciamiento penal". Véase: Historia de la Ley 20.084 (2005: 7).

${ }^{9}$ Historia de la Ley 20.084 (2005: 12).

${ }^{10}$ Historia de la Ley 20.084 (2005: 23-29).
} 
pretendían configurar un comportamiento distinto del sistema procesal penal tratándose de adolescentes, el proyecto se aprueba con un poco menos de la mitad de artículos referidos a lo procesal-dejando fuera las normas procesales de ejecución-.

El resultado es un proyecto que en lo formal no articula un procedimiento penal específico para los adolescentes -reservándome para el desarrollo del trabajo la interrogante de si acaso esto es necesario-, por mucho que el lenguaje del artículo 27 inciso primero demuestre un gran optimismo al señalar que "La investigación, juzgamiento y ejecución de la responsabilidad por infracciones a la ley penal por parte de los adolescentes se regirá por las disposiciones contenidas en la presente ley y supletoriamente por las normas del Código Procesal Penal", lo cierto es que el CPP es el principal instrumento procesal que se aplica a los adolescentes para hacer efectiva su responsabilidad penal y las escazas normas existentes en el Título II de la LRPA únicamente modifican de manera muy precisa y en aspectos acotados el comportamiento de las normas generales de los adultos tratándose de adolescentes. Lo que se presenta como supletorio es claramente lo principal. ${ }^{11}$

Lo anterior a primera vista pudiese no ser problemático. Un adecuado esfuerzo dogmático sobre la LRPA y sumado al punto positivo de contar con uno de los buenos Códigos Procesales Penales de la región, pudiese dar por satisfecho la mayoría de los derechos y garantías contenidos en los artículos 3, 12, 37 y 40 de la CDN, por mencionar algunos. Sin embargo, el problema es más complejo y radica en cómo se entienda el mandato de especialidad para la justicia penal juvenil que emana de la CDN, respaldada además por una serie de otras reglas y directrices emanadas del sistema internacional de DDHH. En síntesis, la pregunta no es otra sino qué es la especialidad en el ámbito procesal penal juvenil. De qué manera distinta se comporta, o debiera comportarse, el sistema procesal penal tratándose de adolescentes imputados, sobre todo en atención a que el contenido de los derechos y garantías procesales de la CDN no difiere, en principio, de manera sustancial de aquel establecido en instrumentos generales o cuyos destinatarios son todos los seres humanos. A nuestro parecer, la respuesta que se asuma en relación a este ámbito no sólo permite testear a nivel general el grado de cumplimiento que como Estado hemos dado a la CDN en lo relativo a la justicia penal juvenil, sino que puede orientar la respuesta especifica -esta y otras más- que se brinde en torno a la procedencia o no de una institución concreta en la justicia penal juvenil como es el "abreviado". De este modo, con las prevenciones realizadas se abordará el mandato de especialidad.

\footnotetext{
${ }^{11}$ En este sentido Duce (2003: 100-101): “Esta vinculación es tan intensa que me parece posible afirmar que el proceso penal establecido en el nuevo Código Procesal Penal es el proceso para los adolescentes en este proyecto".
} 


\subsection{Aproximaciones a la especialidad procesal penal juvenil}

\subsubsection{Consideraciones previas}

Como reflexiona Maldonado (2010: 5-6), sobre el contenido general de la especialidad de la responsabilidad penal juvenil, aún permanece una fuerte tendencia a comprender la especialidad únicamente como una dirección más enérgica hacia la prevención especial, de esta forma el contenido de lo "especial" se torna tenue y difuso. Con el peligro concreto de que la especialidad, en ese contexto, más bien pasa a ser una cuestión únicamente de grados [de intensidad], por oposición a un elemento con alcance propio. ${ }^{12}$ Siendo un claro ejemplo, en el ámbito procesal, lo que se cuestiona el autor, "¿cuál es la novedad de que la privación de libertad sea el último recurso si en adultos rige el mismo parámetro a partir del principio de última ratio?". Detrás de esta forma de comprender la especialidad -consciente o inconsciente-, "subyace la lógica que la especialidad se traduce finalmente "en una especie de rebaja o reducción de los índices de aflictividad de la sanción, una respuesta simplemente más blanda, emanada de lo que se considera es un déficit presente en el adolescente. En ello se toma como punto de partida el que la normalidad en el ámbito de las relaciones sociales se desarrolla bajo las condiciones propias de la adultez y, consecuencialmente, se pasa a comprender al adolescente como una especie de sujeto en formación, un verdadero actor incompleto, al que necesariamente le cabe por ello un menor grado de responsabilidad (personal) a partir de su capacidad disminuida" (Maldonado, 2010: 6).

Lo anterior nos alerta desde ya, que para entrar al problema del contenido de la especialidad "procesal" existe un riesgo elevado de finalmente no dar con su contenido, por la vía de comprenderla únicamente como una aparente expresión menos intensa del poder penal manifestada a través del procedimiento en razón de las características generales de la adolescencia. De esa forma, el análisis sobre el contenido de la especialidad [procesal] corre el riesgo de volverse circular, toda vez que las normas de la LRPA se configuren como reglas tópicas -en términos de Maldonado (2010: 12)- que únicamente modifican el desarrollo ritual del procedimiento fijado a nivel general para los adultos, no se permite determinar el sentido, o la carencia del mismo, que puedan tener en particular algunas instituciones jurídico procesales en el caso de los procedimientos penales juveniles. Se trata, por ende, de un camino aparentemente sin salida.

\footnotetext{
${ }^{12}$ En igual sentido advierte Cillero (2009: 13), quien sostiene que "las diferencias entre el Derecho penal de adolescentes y el de adultos se enmarcan, básicamente en lo cualitativo: no se reducen a la mera intensidad de la respuesta punitiva".
} 


\subsubsection{Dimensiones del principio de especialidad procesal}

En Chile el desarrollo del contenido de la especialidad se ha producido principalmente en lo que dice relación con lo sustantivo (Maldonado, 2014), campo del derecho penal -y del sistema de sanciones y su ejecución-, más que en lo procesal penal, en este último los esfuerzos son pocos. El principal esfuerzo por señalar el contenido de la especialidad a nivel procesal es el realizado por Duce. ${ }^{13}$

La propuesta ${ }^{14}$ aludida tiene por objetivo identificar y analizar los principales criterios y estándares desarrollados en el ámbito del derecho internacional para fijar los alcances del "principio de especialidad", o derecho a un tratamiento especial, como le denomina. Y busca específicamente, dar con las consecuencias concretas que el principio conlleva en la regulación de instituciones y garantías procesales de los adolescentes (Duce, 2013a: 45). De este modo, pareciera ser que la propuesta más que buscar la naturaleza o condición de la especialidad en el ámbito procesal, tiene por finalidad algo mucho más concreto en relación al principio. Este exhaustivo esfuerzo identifica tres ejes -y dentro de ellos una serie de componentes- en que se manifiesta el derecho a un tratamiento diferenciado (Duce, 2013a: 53-105). Todos estos ejes tienen como premisa el elemento -no siempre relevado en su importancia- que el mandato de especialidad es de carácter sistémico (art. 40.3 CDN en relación con el principio de efectividad, art. 4). Es decir, apunta al sistema penal juvenil en su conjunto: instituciones, normas y procedimientos. De modo que, la [re]definición de varios de los elementos que componen el sistema tiene un sentido y justificación que no se encuentra únicamente en las manifestaciones concretas que adquiera cada componente del sistema, se trata de un abordaje integral que no debe perderse de vista al momento de que los Estados incorporen estos aspectos en el ordenamiento jurídico interno.

Los tres ejes permiten apreciar en qué sentido desde el derecho internacional se expresa la especialidad, siendo el primero de ellos -y el que nos convoca particularmente- el "reforzamiento del debido proceso" (Duce, 2013a: 53-83), donde se refiere al procedimiento abreviado al abordar las exigencias más estrictas para la renuncia de derechos que existirían en la justicia penal juvenil. Manifestándose el autor, a favor de la procedencia de esta institución tratándose de adolescentes, postura que será analizada más adelante.

\footnotetext{
${ }^{13}$ En el contexto de un proyecto Fondecyt denominado "El principio de Especialidad en el Derecho penal y Procesal Penal de Adolescentes. Análisis Dogmático y Jurisprudencial” adjudicado para el período 2008-2010.

${ }^{14} \mathrm{La}$ propuesta, por cierto, tiene como premisa una serie de fundamentos empíricos y normativos que inspirarían el mandato de especialidad. Sobre todo en lo que dice relación con los fundamentos empíricos y científicos relativos a las particularidades de la adolescencia y la forma de comportarse socialmente, incluso aquello que fenomenológicamente debiese esperarse, existe amplio consenso en la literatura especializada en que serían aspectos recogidos por la CDN y los demás instrumentos internacionales de DDHH que la tienen como base. Para una síntesis de ellos, véase: Couso (2013: 21-41).
} 
En términos generales -y en lo concerniente a este capítulo- la propuesta en comento, consecuente con el objetivo planteado por el autor, es extremadamente útil porque identifica dimensiones concretas en que se manifiesta el mandato para los Estados de abordar de manera diferenciada el tratamiento de los adolescentes imputados de contravenir la ley penal. Sin embargo, a nuestro parecer, esta aproximación al no optar por materializar un alcance más sustantivo sobre el principio de especialidad tiene implícito el riesgo de no poder cuestionar si acaso la postura especifica que se asuma frente a una determinada institución jurídica procesal es plenamente consistente con el principio de especialidad. Esto, sin duda, no es problemático cuando se trata de estándares que se encuentran bastante cercanos a una formulación de reglas (varias de las garantías contenidas en los artículos 37 y 40 de la CDN encuentran regulación casi de manera expresa en el CPP). Pero la necesidad de contar con un sustrato mayor sobre el principio de especialidad se presenta cuando se trata de garantías mucho más generales y que pudiesen resultar aplicables en varias oportunidades y bajo diversas condiciones en el Proceso penal. Digamos, de la formulación contenida en el art. 40.2 b) iv) de la CDN "Que no será obligado a prestar testimonio o a declararse culpable...", existe todavía un trecho más largo que debiese transitarse para determinar el procedimiento abreviado como compatible con un sistema penal juvenil. Ámbito que, a nuestro parecer, es más propio del segundo eje que identifica el autor, como se indicará.

\subsubsection{Contenido del principio de especialidad procesal}

Una segunda propuesta de especialidad en lo Procesal penal que es posible identificar es la formulada por Cillero ${ }^{.15}$ En un primer momento el autor (Cillero, 2003: 53-86), descartando la posibilidad de diseñar un sistema de enjuiciamiento autónomo del derecho procesal penal, señala que el objetivo del mandato de la especialidad consiste en "establecer un sistema especializado de juzgamiento que reconozca al niño como un especial sujeto de derecho y, en consecuencia, en lugar de pretender introducir o trasladar las "garantías del proceso penal" a un sistema de juzgamiento autónomo, es necesario incorporar en el proceso penal un conjunto de garantías especiales que permitan incluir la perspectiva de "protección integral" en esta variante del proceso penal". Es decir, la especialidad estaría dada por la "profundización, complementación y reforzamiento" de las garantías que integran el debido proceso (Cillero, 2003: 76).

$\mathrm{Al}$ autor le preocupa que ese objetivo protector que plantea, incluir la perspectiva de la protección integral, se confunda con las características del sistema tutelar de menores y, al mismo tiempo, con los aspectos comunes que este comparte con el modelo socio-educativo (alemán). Y el motivo pasa porque tanto el ideal protector pregonado por el sistema tutelar como por el modelo educativo

\footnotetext{
${ }^{15}$ Hago la salvedad que la propuesta del autor no se encuentra contenida en un único trabajo que haya tenido tal finalidad, sino que es una síntesis propia de diversos artículos del autor desde los cuales es posible construir su postura.
} 
alemán en los hechos fue incapaz de limitar la pretensión punitiva del Estado respecto de los niños. De forma tal, que en el contexto del reconocimiento que efectúa la CDN de los niños como sujetos de derecho deben extraerse dos consecuencias a juicio del autor: i) la plena vigencia del estatuto constitucional general destinado a tutelar el derecho a la libertad y limitar el ius puniendi; y, ii) la aplicación complementaria del su estatuto jurídico especial destinado a la protección integral de sus derechos y desarrollo (Cillero, 2003: 76-77).

Para Cillero lo anterior implica, haciendo referencia al principio de formalidad del procedimiento de Roxin, el cual tiene por objetivo servir "directamente a la protección de la dignidad humana", que en el proceso se deben respetar aquellas particularidades reconocidas jurídicamente a los niños. De este modo, no podría haber un proceso especial que "realice" un "derecho penal de adultos", ni tampoco se podría "realizar" un derecho penal de adolescentes a través de la mera remisión a la normativa del proceso penal de adultos (Cillero 2003: 81-82). Lo anterior en razón de cierto nivel de simetría que debe existir entre el derecho penal sustantivo y el procesal, vinculada íntegramente a los fines que se prediquen respecto del primero.

Asumida la obligación de incorporar la variante de protección del desarrollo de los adolescentes al proceso, junto a la de plena vigencia de todas las garantías destinadas a limitar el ius puniendi, la interrogante que surge es cuál de estas dos será la que organice la configuración del proceso. Planteado de otro modo, cuál es el rol de la protección al desarrollo en el Proceso penal juvenil en el contexto de un garantismo reforzado. Y la respuesta dada por el autor, es que el proceso no puede articularse sino en base a las garantías penales y del debido proceso, con garantías reforzadas, que deben tener en especial consideración la situación de los adolescentes por cuanto se encuentran en proceso de desarrollo. Siempre en lenguaje de límite a la intervención del ius puniendi, nunca con el carácter de función de "promoción del desarrollo", que conlleva el riesgo de expandir los instrumentos penales a otros ámbitos fuera del control y sanción del delito (Cillero, 2003: 81-82). Hasta aquí entonces, puede sostenerse que un proceso [penal] será especializado en la medida en que la protección del desarrollo del adolescente opere como un límite más a la intervención penal.

Luego, en un segundo momento -y sobre las bases del rol atribuido al estatuto jurídico especial destinado a la protección integral en el marco del proceso penal-, el autor pone particular énfasis en la autonomía de los adolescentes vinculada a su derecho a defensa. Y esto se debe a que para los adolescentes el paso de un sistema tutelar inquisitivo donde el derecho a defensa carecía del carácter de garantía o era inexistente, a uno adversarial de responsabilidad penal, no fue sinónimo de garantía [de ejercicio] del derecho a defensa. Dicho de otra forma, para que el derecho a defensa de los adolescentes pudiese resultar efectivo y se cumplan todos los valores y objetivos del sistema, abandonándose el sistema tutelar, todavía restan ámbitos por resolver que exceden al diseño normativo contemplado en el CPP del derecho a defensa. El reconocimiento y operatividad 
del derecho a defensa (concebido en el Proceso penal de adultos) respecto de los adolescentes, no es garantía suficiente de efectividad.

En este contexto, el punto de partida es el reconocimiento del adolescente como sujeto de derechos, en concreto, como un sujeto de derechos competente para participar en el proceso y en su propia defensa. Ahora bien, esta aseveración no implica negar las particularidades que presentan los adolescentes. De ahí que, si el proceso efectivamente tiene la obligación de incorporar elementos destinados a la protección del desarrollo de los adolescentes, entonces debe hacerse cargo de las particularidades que los adolescentes presentan. Y estas no son otras sino que las diversas competencias y capacidades que exige de ellos el Derecho penal y Procesal penal, las cuales no siempre se pueden dar por satisfechas a priori. Por este motivo, el principal motor para la mayor realización de las capacidades del adolescente y, consiguientemente, del ejercicio de sus derechos en el proceso, sea precisamente su abogado defensor, ${ }^{16}$ discutiéndose entonces cuál es el rol específico que le corresponde a este último en el escenario descrito. Si bien el autor reconoce que es necesario que los diversos actores posean niveles significativos de expertizaje en materia de responsabilidad penal adolescente, la defensa penal es el elemento que dota de mayor contenido a la especialidad (Cillero, 2009: 9-28). Esto planteado no desde un punto de vista institucional, sino que más bien desde una lógica funcional. Toda vez que, la finalidad de la especialidad sea respetar y promover la autonomía de los adolescentes, así como fomentar efectivamente la participación en su propia defensa, no cabe dudas que esto queda entregado principalmente a la defensa penal. ${ }^{17}$

La postura que se puede extraer del trabajo de Cillero permite dar con el contenido o, como le he denominado antes, sustrato del principio de especialidad. En el contexto de un derecho penal garantista, el principio de especialidad implica en lo procesal contar con un garantismo reforzado. Que está dado por añadir un límite adicional al poder penal que complementa el conjunto de garantías penales y del debido proceso. ${ }^{18}$ Donde la protección del desarrollo del adolescente como principio que incide en la configuración del proceso ordena el respeto y fomento de la autonomía, porque solo en esta forma puede llegar a considerarse que existirá una defensa efectiva en el proceso penal (tanto material como técnica). Y dado que la autonomía de los adolescentes, en razón de las particularidades que estos presentan por sus menores competencias y capacidades, es un elemento deficitario, solo en la medida en que esto se "corrija" se puede hablar de un efectivo ejercicio de derechos por parte de estos.

\footnotetext{
${ }^{16}$ Lo que sin duda lleva a abordar otro tipo de problemas planteados por el autor, principalmente relacionados a las hipótesis en que el defensor podría ir contra la autonomía de su cliente.

${ }^{17}$ En este sentido el autor hace referencia a la tendencia mayoritaria existente en Estados Unidos sobre el rol de la defensa penal de adolescentes, aspecto que se abordará con más detalle en los capítulos III y IV.

${ }^{18}$ En este sentido la dimensión que Cillero le atribuye al interés superior del niño en el ámbito de la Responsabilidad Penal de Adolescentes, véase: Cillero (2005: 97-103).
} 
En el contexto anterior, y plenamente compatible con la propuesta antes señalada, se encuentra la postura de Garrido (2011: 7-28). Si bien no se trata de una aproximación especifica de la justicia penal, aporta con una serie de elementos que enriquecen el debate. Para el autor es igualmente un elemento clave en la aproximación al contenido de la especialidad, la noción de los niños como sujetos de derechos y "autónomos". En términos sintéticos su postura es, si el proceso judicial en su tradición liberal -independiente de las particularidades que presente en otros ámbitos el proceso penal- es un medio de debate racional que se ha establecido por el Estado para resolver determinados conflictos, entonces la autonomía de los sujetos es un elemento clave para la configuración de los procedimientos. Debiendo entonces, considerarse particularmente que tratándose de los niños, la autonomía se presenta de una manera diferente, "progresivamente". De esta forma, "un procedimiento especializado es la consecuencia necesaria del reconocimiento y de la probabilidad de que los niños manifiesten su autonomía, es decir, puedan ejercer ellos mismos los derechos de los que son titulares" (Garrido, 2011: 15). Planteado así, la noción de especialidad tendría un sustrato palpable, su contenido está orientado a garantizar que los niños en el marco del procedimiento puedan manifestar su autonomía y ejercer ellos mismos sus derechos, podemos añadir de manera "progresiva".

Reconocida a todos los niños la capacidad de goce, de los derechos universales y de otros específicos atendida la etapa en que se encuentran, el problema se traslada entonces al ámbito de la capacidad de ejercicio. Y al respecto, es claro que no se tiene titularidad de los derechos de manera progresiva, lo que puede suceder es que el ejercicio de estos pueda verificarse gradualmente (Aláez, 2007: 179-210). De ahí que, la noción de especialidad lleve consigo el mandato de que los procedimientos en los que intervengan niños, sin anular la idea misma del proceso, consideren de manera general y especial que en "este medio de debate racional" hay sujetos que presentan dificultades para ejercer de manera autónoma sus derechos. Dicho de otra forma, se trata de sujetos que no están en condiciones de autoprotegerse (Aláez, 2007: 189-202).

En este sentido, aun cuando existan ciertas garantías mínimas de los adultos que se ven reforzadas tratándose de los adolescentes, todavía la interrogante posible de formular es, sí acaso, esto permite de manera efectiva superar aquellos déficits que pueden presentar los adolescentes para ejercer su autonomía en el marco del procedimiento. Es decir, se trata de que un procedimiento es especial [sólo] si está diseñado para corregir aquellos déficits de autonomía que presenten los niños. Por este motivo señalábamos antes que el camino para analizar la procedencia del abreviado en el proceso penal juvenil requiere de un trayecto más extenso. Requiere comprobar si acaso esas mayores exigencias que puedan existir para la renuncia de derechos son consistentes con una noción de especialidad que apunte a corregir los déficit que puedan presentar los adolescentes para ejercer su autonomía y el conjunto de derechos de que son titulares. De lo contrario el riesgo presente es el que aludía Maldonado, asumir la especialidad únicamente como una respuesta menos intensa a secas - que inclusive en determinados casos se puede lograr esa menor intensidad para 
el sujeto imputado por la vía de ser más exigente con el sistema en determinadas instancias y no mejorando su situación-, sin una finalidad concreta. Finalidad, que por lo demás, es consistente con uno de los principales objetivos del proceso penal, la realización de las garantías (Duce y Riego, 2007: 28-31).

\subsubsection{Síntesis}

De las dos últimas posturas expuestas, queda en evidencia que el proteger el desarrollo de los adolescentes pasa porque estos no se encuentran en condiciones de protegerse autónomamente $\mathrm{y}$, entonces, requieren de una protección que proviene de fuera (heteroprotección) para que puedan llegar a alcanzar la capacidad de autoprotegerse (Aláez 2007: 189-192). Este déficit de capacidad de autoprotegerse, o de autonomía, dado la etapa de desarrollo en que se encuentran los adolescentes, es el objetivo de la especialidad del proceso penal juvenil. En síntesis, promover su superación, tanto a nivel sistémico (los diversos ejes identificados por Duce) como a nivel del rol específico del principal responsable de representar los intereses y defender los derechos de los adolescentes (la defensa penal). De esta forma, el poder penal se encuentra con una mayor restricción, toda vez que hay un proceso que no le va a permitir intervenir más allá de las capacidades que detenten los sujetos (consistente con la idea de un Derecho Penal de culpabilidad).

Dotado de contenido el principio de especialidad -como vimos, estrechamente vinculado a la noción de los adolescentes como sujetos de derechos y que poseen una autonomía que es continua pero progresiva-, nos parece que de la síntesis de las formulaciones expuestas (consistentes entre sî) es posible formular un estándar general para medir la presencia del principio -algo útil para nuestro propósito-, y este consiste, en que habrá especialidad (en los diversos niveles en los que está debe manifestarse conforme a la $\mathrm{CDN}$ ) en la medida que se permita efectivamente el [auto]ejercicio de los derechos de los adolescentes, conforme a las particularidades que estos presentan. En este sentido, por ejemplo, cuan especializado debe ser el Proceso penal juvenil -desde el punto de vista de su diseño normativo-, sostendremos que lo suficiente para permitir la realización efectiva de los derechos de los adolescentes. Retornaremos a esta idea más adelante.

\section{El procedimiento abreviado: dimensiones y problemas}

\subsection{Justificación y alcance de la institución}

La reforma procesal penal, en concreto el Código Procesal Penal, concibió al derecho a un juicio oral como la garantía básica del sistema y el eje de todos los demás derechos (Riego, 2001: 473). De hecho, el juicio oral representa en la estructura y geografía del proceso el curso por defecto que debiese tener siempre el sistema de enjuiciamiento instalado por la reforma. Es decir, el proceso siempre tendría una orientación hacia la instancia de mayor expresión e intensidad de las 
garantías penales y procesales penales y donde se aprecian con más fuerza los principios del sistema. Sin embargo, por diversos motivos la configuración de los nuevos procedimientos penales latinoamericanos en su direccionamiento hacia variantes acusatorias o adversariales incorporaron mecanismos de negociación y de resolución alternativa de conflictos, ${ }^{19}$ lo cual en principio pudiese resultar paradójico en palabras de Riego (2001: 453) pero tiene claras justificaciones.

La incorporación de los mecanismos antes señalados, entre los que se encuentra el procedimiento abreviado, tenía por objetivo contribuir a la viabilidad de la política pública de reforma al sistema de justicia criminal. Donde una variante que debe ser siempre considerada en el diseño y ejecución de toda política pública son los costos que irroga al Estado. Como señala Riego, la reforma tuvo por objetivo, por una parte, dar respuesta a la necesidad de aumentar sustancialmente las garantías del proceso penal y, por otra, mejorar la eficacia del sistema de justicia criminal específicamente en cuanto a obtener decisiones oportunas en aquellos casos de mayor gravedad o que mayor preocupación ciudadana generaban (Riego, 2001: 454). En este contexto, el abreviado se presenta como una forma de captar a quienes pregonaban un fuerte interés en que el nuevo sistema fuese eficaz. Por este motivo, puede estimarse que contribuyó a la viabilidad de la implementación de una reforma de gran magnitud, especialmente en lo que se refiere a agrupar los diversos intereses y actores involucrados, aspectos base de su posterior apoyo político y legitimidad.

En el sentido anterior, resultaron claves estudios de índole financiera y de rentabilidad social respecto al empleo del abreviado, así como proyecciones definidas sobre el impacto estadístico que debería tener en la solución de los miles de casos que conociera el nuevo sistema de enjuiciamiento (Riego, 2001: 455). Desde el discurso de la política pública de reforma el abreviado se erige, junto a otras nuevas instituciones jurídico-procesales, como uno de los mecanismos que puede mantener estable los costos del sistema para el Estado, inclusive aspirar a producir algún tipo de ahorro en el largo plazo (Riego, 2001: 456). Concebido con esta justificación, lo cierto es que el abreviado en relación a los objetivos del nuevo proceso penal, únicamente apunta como institución a un mundo, al de la "eficacia".

Luego, dejando de lado los fundamentos de la incorporación de esta institución en el nuevo proceso penal, se ha discutido cual es efectivamente la "versión" - de las existentes a nivel comparado- incorporada en el CPP, en palabras de otro autor "la definición de sus contornos, es decir, hacia la precisión del objeto del consenso o pacto" (Rodríguez, 2011: 501). Y esta discusión pareciera entrever que esta institución no puede ser comprendida únicamente en base al tenor de la norma que lo define y al conjunto de la regulación que se haga,

19 Véase: Langer (2001: 97-133). Para un mayor desarrollo de este proceso de difusión e incorporación de ideas jurídicas procesales propias del derecho Estadounidense, Véase: Langer (2007). Y más específicamente véase: Langer (2004). 
sino que necesariamente debe analizarse en base al conjunto de otras facultades que constituyen en plenitud el poder del que se encuentra dotada la persecución penal y, consecuencialmente, de la posición del imputado frente a este poder.

Para Riego, el procedimiento abreviado "consiste en la posibilidad de que las partes puedan acordar una forma de procedimiento diversa, consistente en proceder a un debate simplificado frente al juez encargado de controlar la actividad de instrucción, al término del cual este último pronunciará sentencia" (RIEGO 2001: 457). $\mathrm{El}$ autor no desconoce, producto además de una serie de cambios que se efectuaron, que la regulación puede ser defectuosa, ${ }^{20}$ principalmente porque la regulación del abreviado daría cuenta de una "mixtura de dos lógicas" que provocan focos de conflicto. Una lógica es sostener que se trata de una regulación similar a la existente para las declaraciones de culpabilidad estadounidenses ("guilty plea" obtenida como consecuencia de un proceso de negociación "plea bargaining"), dado la no disputa de los supuestos fácticos de la acusación. La segunda, sería comprender al abreviado como un acuerdo sobre el procedimiento, como un cambio de rito, como la renuncia al juicio, donde el fundamento de la sentencia no es la aceptación del imputado sino la evidencia que respalda la acusación fiscal (Riego, 2001: 462-463). A juicio del autor la lectura acertada es la segunda, lo que, por cierto, no obsta a las críticas que a esta institución pueden formularse y que de hecho el mismo esboza.

Del Río opina que la formula chilena si bien reconoce el principio de consenso en el proceso penal, no resulta claro que sistema de consenso ha quedado plasmado en el CPP. En la misma línea de Riego, cuestiona si se trata de un consenso sobre el rito procedimental o, más bien, se trata de un consenso sobre el mérito del proceso de carácter fáctico y jurídico (Del Río, 2008: 158-160). Para Del Río esta última opción requeriría que las partes en el proceso se encontrarán constitucional y legamente habilitadas para ello, porque, entre otras razones, se estaría en presencia de una amplia inaplicación de la legalidad, tanto procesal como sustantiva, por ejemplo cuando se acuerda un contenido factico con independencia de la realidad (Del Río, 2008: 163). Lo que no sucede en el caso chileno. Para el autor el único consenso admisible en nuestro esquema sería el relativo al rito procedimental, pero no sobre el mérito procesal (Del Río, 2008: 164). Es decir, la única excepción a la legalidad estaría dada por la posibilidad de someter el asunto a un procedimiento alternativo (rito procedimental), lo que no obsta a la obligación de acusar y sostener la acusación ni mucho menos cesa el deber de acusar por el hecho delictual que efectivamente existe (merito procesal). De esta forma, el Ministerio Público no podría disponer de los hechos con relevancia jurídico penal (Del Río, 2008: 163). En igual sentido, a través de una justificación diferente, se manifiesta RODRÍGUEZ, quien es partidario de permitir la modificación de los presupuestos facticos de la acusación solo en la medida en que estos no sean esenciales (Rodríguez, 2011: 504-505).

\footnotetext{
${ }^{20}$ Más categórico Del Río al sostener que la regulación es “escasa, lagunar, ambigua e incluso, a veces, incoherente", véase: Del Río (2008: 160).
} 
En el plano teórico no se encuentra en la doctrina una lectura del procedimiento abreviado que le atribuya elementos similares a la versión extrema que sería el "plea guilty" estadounidense y, por lo mismo, las interpretaciones deambulan en la precisión de un modelo mucho más restringido. No obstante, existe bastante uniformidad en que el proceso como está concebido presenta importantes focos para que en la práctica el sistema se comporte de manera distinta al diseño teórico, lo que vendría dado por dos razones, (i) los defectos técnicos de la regulación y (ii) que independiente de la regulación precisa que se haga existirían ciertos elementos propios de la naturaleza de este tipo de instituciones que, de todas forma, generan incentivos negativos para los actores del sistema de justicia criminal. De aquí se derivan una serie de críticas jurídicas que nos parece necesario recoger.

\subsection{Principales problemas jurídicos que presenta el procedimiento abreviado}

Sin ningún afán más que facilitar la presentación sintética de los problemas jurídicos que presenta el abreviado y este tipo de instituciones, considero pedagógico diferenciar dos niveles dentro de ellas. Primero, exponer aquellos generales de contenido jurídico que se han formulado a este tipo de procedimientos. ${ }^{21} \mathrm{Y}$ segundo, dar cuenta de aquellos específicos que se han formulado a nuestro procedimiento abreviado.

\subsubsection{Problemas generales:}

1. Independiente de la legitimación de este tipo de mecanismos, existe un peligro de que la práctica de los acuerdos provoque una significativa perversión burocrática y policial de una parte importante del sistema penal. Transformando de esta forma el derecho a un juicio oral en un verdadero lujo reservado a quienes pue dan afrontar sus costos y riesgos (Ferrajoli, 2001: 45).

2. Este tipo de mecanismos, que dotan de amplia discrecionalidad y escaso control a los organismos de la persecución penal, pueden constituir una reforma no declarada, indirecta, al derecho penal sustantivo, principalmente por la vía de la marginación del momento jurisdiccional en sentido propio y por la creciente divergencia entre pena prevista, pena impuesta y pena cumplida (Ferrajoli, 2001: 49).

3. En aquellos mecanismos, especialmente los que permiten negociación de pena, es cuestionable si se está ante un "procedimiento alternativo" (al juicio oral) o, más bien, se trata de "medidas alternativas al proceso", con las implicancias que esto conlleva (Ferrajoli, 2001: 47-48).

\footnotetext{
${ }^{21}$ Como se ha señalado, intencionalmente se ha decidido excluir, en razón del objeto del trabajo, aquellas críticas de índole política, sociológica y criminológica que pueden formularse. Las que, sin lugar a dudas, pueden resultan incluso más significativas que las jurídicas.
} 
4. Este tipo de mecanismos tienden a desfigurar los diseños "puros" de los sistemas de enjuiciamiento penal. Resultan extremadamente complejos de controlar. Por lo mismo, prefiguran un sistema diverso (de un sistema contradictorio de atribución de culpabilidad a un sistema no contradictorio de concesiones) (Langbein, 2001: 3-29). En síntesis, serían inconsistentes con la fundamentación del sistema acusatorio.

5. Este tipo de mecanismos, con más notoriedad en variantes más extremas, son altamente coercitivos. Por la vía de hacer sumamente costoso ejercer el derecho a un juicio oral (supone el mismo dilema moral que se presenta para detener la tortura de la que se es objeto) (Langbein, 2001: 15-20).

6. Fomenta una lógica de intercambio perverso donde se cambiaría pena por prueba o por garantías (Ferrajoli, 2004: 568-569).

7. Estos mecanismos están en contradicción con algunos principios del Estado de derecho, en particular con el principio de inocencia y el derecho a un juicio oral, cuyo carácter de renunciable es discutible (Díaz, 2001: 251-276).

\subsubsection{Problemas particulares:}

1. Aun cuando se estime que el CPP no contempla explícitamente la negociación de penas (Riego, 2001: 463), de conformidad al art. 407 inc. 3 se aprecia un claro incentivo a que se generen espacios de negociación no regulados (Del Río, 2008: 166).

2. Sosteniendo la existencia de un espacio de negociación de pena no regulada, la variante coercitiva de este tipo de mecanismos encuentra una ventana. Lo que sumado a la inexistencia de límites claros para la duración de la prisión preventiva genera un incentivo fuerte a acceder al abreviado para poner término al castigo informal (Riego, 2001: 473-475).

3. Aumenta la discrecionalidad del Ministerio Público, extendiéndose más allá del método del juicio al ámbito del contenido del mismo, con el consiguiente riesgo de sustitución de las potestades jurisdiccionales (Del Río, 2008: 178).

4. Aun cuando no se establezca expresamente un sistema de negociación de penas, el sistema de premiar la renuncia del ejercicio de los derechos con una rebaja de pena, implica igualmente un castigo al ejercicio de los mismos (Riego, 2001: 473-474).

Expuestas aquí las principales críticas jurídicas al procedimiento abreviado y habiendo desarrollado antes nuestra aproximación al principio de especialidad, corresponde ahora identificar si acaso los adolescentes pudiesen enfrentar además de estos problemas otros significativos. 


\section{Problemas específicos de los adolescentes en el proceso penal}

Como señalamos antes, el camino para determinar la procedencia del procedimiento abreviado tratándose de adolescentes es más extenso que un análisis referido exclusivamente a la renuncia de derechos. De esta forma, a los problemas que presenta el procedimiento abreviado (en general para los adultos) corresponde adicionar aquellos particulares que puedan presentar los adolescentes en el Proceso penal que inciden a la hora de pronunciarse sobre la procedencia del procedimiento abreviado en la justicia penal juvenil. Planteamos "adicionar" porque, aun cuando hemos tratado de dejar de lado en este análisis la variable empírica del funcionamiento del sistema, jurídicamente no existen motivos para pensar que los problemas (generales) del abreviado se presentan de manera distinta (mitigando su efecto) tratándose de adolescentes (Berrios y Vial, 2011) considerando los problemas específicos que ellos presentan. Por el contrario, existen una serie de razones que permiten sostener que tratándose de adolescentes, estos siempre están en peores condiciones que los adultos.

En este capítulo plantearemos dos problemas que aun cuando permean de manera constante la discusión sobre la justicia penal juvenil, están especialmente presentes en el caso del abreviado. A saber, (i) las competencias y capacidades de los adolescentes y (ii) la necesidad de diferencias en el proceso penal aplicable a los adolescentes, respecto del general establecido para los adultos. Siendo estos problemas retomados en el capítulo posterior como se señaló en la introducción.

\subsection{Competencias y capacidades de los Adolescentes}

Existe consenso a nivel doctrinario y no solo jurídico, en que los adolescentes son individuos que en los hechos aún no cuentan con el reconocimiento de las capacidades atribuidas a los adultos o mayores de edad (Maldonado, 2014: 18). Y de esto se derivan no solo una serie de consecuencias desde el punto de vista del Derecho Penal sustantivo -y del ámbito de ejecución- sino que también desde el ámbito procesal. Sin embargo, a la hora de determinar cuáles son aquellas competencias y capacidades que se requieren de un individuo para afrontar el proceso judicial, en concreto el criminal, no solemos ahondar mayormente en esto. ¿Requiere acaso el mismo nivel de capacidades o competencias el decidir en cuál lugar firmar (tratándose de la medida cautelar de firma periódica en aquellos casos en que el juez de garantía le consulta al imputado), que el aceptar a un sujeto en particular como defensor penal público o el decidir ir a juicio oral o, a la inversa, el decidir no ir a un juicio oral y asumir la responsabilidad de los hechos?

La respuesta a lo anterior es negativa, no se trata de aspectos que exijan de los individuos idénticos niveles de competencia. Y para entrar en este ámbito recurriremos a la doctrina que se ha desarrollado críticamente en torno a la justicia juvenil en Estados Unidos, donde existe un mayor desarrollo en estas temáticas. 
Bonnie y Grisso sostienen que la necesidad de contar con una noción de "competencia[s] para ser juzgado en procedimientos criminales" está ligada a tres propósitos sociales: i) preservar la dignidad del procedimiento criminal; ii) reducir el riesgo de condenas erróneas; y, iii) proteger la toma de decisiones autónomas de los acusados. Especialmente, esta última idea está referida a que la toma de decisiones sea realizada personalmente por el acusado, es él o ella quien debe tener las habilidades necesarias para efectuar una toma de decisiones autónomas (Bonnie y Grisso, 2000: 76). Detrás de esto, llevándolo a nuestra terminología, pareciera ser que la defensa técnica no puede suplir aquellos ámbitos donde no existen las habilidades personales -que requiera un sujeto concreto- para desarrollar una defensa material. Podrá ser otro el rol de la defensa técnica, pero en principio este no consiste en suplir (o subrogar en) el vacío de las competencias o capacidades de las cuales carece un acusado en concreto para participar en su propia defensa.

Los autores señalados, sustentándose en jurisprudencia emanada de su país, sostienen que es posible especificar aquellas competencias y habilidades requeridas por la denominada "competencia para ser juzgado". Esta engloba dos componentes que aun cuando están relacionados pueden ser separados (Bonnie y Grisso, 2000: 76). El primero de ellos se refiere a las "competencias para ayudar al abogado". Es decir, se trata de las condiciones legales mínimas requeridas para participar en la propia defensa. Estas son:

1. Comprender los cargos y los elementos básicos del sistema adversarial (comprensión).

2. Apreciar la situación que se tiene como acusado en la persecución penal (apreciación).

3. Relacionar la información pertinente en lo relativo a los hechos del caso para el abogado (razonamiento) (Bonnie y Grisso, 2000: 76).

Luego, el segundo componente se refiere a las "competencias decisionales". Y el motivo de este tipo de competencias se explica en que no necesariamente un acusado que puede "ayudar" a su abogado es competente para adoptar decisiones en el marco del proceso que se desarrolla en su contra. Como señalan los autores citados, la toma de decisiones claramente involucra tareas cognitivas adicionales a aquellas requeridas para ayudar a su abogado, ${ }^{22}$ para ayudar a defenderse a sí mismo, en otras palabras. De esta forma, cuatro serían los criterios que podrían ser empleados para determinar las competencias decisionales:

1. La capacidad de comprender la información relevante para el asunto específico en que se debe tomar una decisión (comprensión).

2. La capacidad de apreciar la situación que se tiene como acusado respecto a una decisión legal específica (apreciación).

\footnotetext{
22 Los autores reconocen que en este campo la jurisprudencia aún no ha emitido un pronunciamiento definitivo sobre cuales son estás competencias decisionales.
} 
3. La capacidad de pensar racionalmente acerca de los cursos alternativos de una acción (razonamiento).

4. La capacidad de expresar una elección entre diversas alternativas (elección) (Bonnie y Grisso, 2000: 77).

Ambos componentes descritos para dar por establecida la "capacidad para ser juzgado" han sido entendidos como aquellas competencias y capacidades que deben estar presentes en un "adulto". Por ende, el problema es evidente, ¿cómo se deben comprender estas exigencias de competencias y capacidades en los adolescentes? ¿Pueden ser todas exigibles por el mero hecho de ser imputables penalmente (si llevamos el asunto a nuestra terminología)? El punto es sumamente complejo y admite el siguiente cuestionamiento. El hecho de que se determine que los adolescentes "pueden responder" penalmente a una sanción en el marco del ideal [re]socializador, ${ }^{23}$ ¿implica que tienen la capacidad de "responder" a cada exigencia del procedimiento que los puede llevar a esa sanción? Dicho de otra forma, cuando se afirma la capacidad del adolescente para solventar su imputabilidad, ¿se afirma cada una de las competencias y capacidades específicas que este requiere para enfrentar el proceso? Incluso, ¿es posible sostener que las capacidades para responder a la sanción sean siempre de una mayor exigencia que aquellas que puede exigir el proceso mismo que conduce a la sanción ? $^{24}$

Todas estas inquietudes nos llevan a un campo con poco desarrollo en nuestra cultura jurídica. Porque pareciera ser que toda la discusión acerca de las capacidades de los adolescentes -y con todos los desacuerdos en la doctrinasiempre ha tenido en un segundo plano el ámbito procesal, como si se tratare de algo de menor entidad. Si se asume el sentido despenalizador del ideal [re]socializador que adquiere la prevención especial tratándose de adolescentes, es dable pensar que existen una serie de decisiones que requieren mayores niveles de capacidad y competencia por parte de los adolescentes en el juicio mismo que en la sanción que se les pueda imponer, en el entendido que el ideal que inspira a las últimas asume un rol limitador de la intervención penal y no la amplía. En términos concretos las interrogantes antes planteadas pueden ejemplificarse de la siguiente forma, ¿requiere mayores capacidades de un adolescente el cumplimiento de los objetivos del plan de intervención fijado para la libertad asistida o la decisión de asumir la responsabilidad por los hechos que se le imputan?

Lo anterior, referido a nuestra tradición, debería llevarnos a relevar o, más bien, no comprender mecánicamente bajo la noción imputabilidad el conjunto de competencias y capacidades que debería tener un adolescente para enfrentar el proceso. Este es justamente uno de los aspectos que otras ciencias y disciplinas distintas a la jurídica han levantado como un problema significativo en el plano de

\footnotetext{
${ }^{23}$ En el sentido despenalizador que le da Couso, véase: Couso (2007).

${ }^{24}$ Otra alternativa es plantearlo en términos de otras capacidades o competencias que exigen diversos ámbitos de la legislación para el ejercicio autónomo por parte de los niños de sus derechos. En este sentido, Véase: Beloff et al, (2015).
} 
la justicia penal juvenil en entornos con más desarrollo del tema. De este modo, el debate se puede abrir, especialmente para dotar de nuevo contenido a las categorías jurídicas involucradas.

En la dirección señalada, también la literatura estadounidense aporta información significativa. Buss indica tres categorías concretas en las cuales los adolescentes se "quedan atrás" respecto de los adultos:

1. Su capacidad para comprender sus derechos.

2. Su capacidad de comprender el proceso de juzgamiento (incluido el rol de su abogado en el proceso).

3. Su capacidad de tomar decisiones que sirvan a sus propios intereses (especialmente aquellos de largo plazo) (Buss, 2000: 244).

Sin duda, que estos aspectos pueden estar presentes con mayor intensidad en aquellos adolescentes más próximos a la edad de inimputabilidad y pueden verse reducidos en adolescentes más próximos a la mayoría de edad. El problema que subyace, en ambos casos, es la falta de evidencia existente sobre esto. Como señala Grisso el tema de las capacidades en los procesos de juzgamiento juvenil es un tema de las dos últimas décadas ${ }^{25}$ y que ha estado relacionado a reformas que se han producido en los procedimientos para los adolescentes. Lo que nos reitera el llamado a estudiar este asunto y la urgencia del mismo. La evidencia comparada, obtenida a través de estudios que involucran diversas disciplinas, es bastante categórica: existen muchos adolescentes que están en riesgo de tener déficits significativos en aquellas competencias y capacidades que se requiere de ellos para enfrentar el juzgamiento y aun así comparecen y son juzgados a diario ${ }^{26}$ (y condenados, por cierto).

\subsection{La necesidad de diferencias en el proceso penal aplicable a los adolescentes}

Adicional al problema de las competencias y capacidades de los adolescentes, se encuentra el problema del procedimiento penal que se les aplica. Este refiere directamente a si acaso tenemos un proceso penal especializado y, de no ser así, cuestionarnos cuán especializado requerimos que sea.

Una de las principales críticas que se formulaban al sistema clásico era que si bien reconocía capacidades de interacción social en los adolescentes que le permitía sostener determinados efectos asociados al grado de autonomía, finalmente este no materializaba una respuesta ni forma de juzgamiento distinta a aquella contemplada para los adultos. La intervención a la que se sometía a los

\footnotetext{
${ }^{25}$ El autor habla de la "última década", pero ha transcurrido otra desde la publicación del libro, véase: Grisso (2000a: 67).

${ }^{26}$ Una exposición de algunos estudios exploratorios realizados en Estados Unidos y Canadá en: Grisso (2000b: 139-171).
} 
"menores" consistía en ser tratados como un adulto (Maldonado, 2014: 20-30). Es decir, el sistema paradojalmente si bien reconocía particularidades a los adolescentes desde el punto de vista de sus capacidades, lo hacía únicamente para atenuar la respuesta penal (imposición de una consecuencia jurídico penal más leve), tratándolos igualmente como un adulto. En lo que al proceso se refiere este no modificaba su ritualidad (en algunos casos a la ritualidad del procedimiento solo se añadía una instancia previa para discutir sobre el "discernimiento" del adolescente).

La noción de que el proceso tratándose de adolescentes debe asumir alguna configuración distinta es algo que también ha estado presente en el debate nacional, ya se cuestionaba al poco tiempo de presentado el Mensaje que da origen a la actual Ley 20.084, la pérdida de un procedimiento que tenía muchas más particularidades que el plasmado en el Mensaje y que si contemplaban las versiones anteriores del proyecto (Duce, 2003: 101).

La problemática acerca de la procedencia del abreviado en la justicia penal juvenil tiene, entonces, un preludio, que está dado primero por llegar a identificar aquellas formas procesales, ritos y/o actuaciones que configuren un proceso efectivamente especializado. Digamos, el problema es el que apuntaba Garrido, cómo se configura un proceso especial sin anular la idea misma del proceso y, pudiésemos añadir, sin caer en las experiencias tutelares o socioeducativas del pasado. Cómo delinear tan claramente un proceso que no permita por ejemplo, que aspectos en principios tan evidentes como si se podían aplicar a los adolescentes las normas procesales de la Ley 18.314, que determina conductas terroristas y fija su penalidad, no necesitaran de modificaciones legales que zanjaran la discusión (Berrios, 2012: 149). Modificaciones, por lo demás, que no tuvieron justificación en una noción clara sobre especialidad vinculada al ejercicio autónomo de derechos, sino que más bien en base a consideraciones de índole humanitarias.

Lo que es posible afirmar, dada la limitación de este trabajo, va en la línea de lo señalado en el primer capítulo. No contamos con un Proceso penal para adolescentes que podamos describir como especializado, al menos en los términos que hemos conceptualizado la especialización. A los adolescentes se les aplica el mismo proceso penal de los adultos. Siendo más críticos aún, podríamos afirmar que el Título II de la Ley 20.084 lejos de convertir al proceso penal en una instancia que considere los déficits de autonomía que presentan los adolescentes y proteja su desarrollo, constituyéndose en un espacio para la realización efectiva de los derechos, lo que hace es facilitar que el proceso de los adultos se pueda aplicar a los adolescentes. No es mera semántica, un Proceso penal especializado debe cumplir ciertos fines como señalamos, nuestro Proceso penal en cambio nos 
acerca mucho a la crítica recogida respecto del sistema clásico donde, en definitiva, los adolescentes eran tratados como adultos, actualmente en lo procesal. ${ }^{27}$

El problema aludido incluso se ha planteado a nivel de la Corte Interamericana de Derechos Humanos. En su OC-17/2002, la Corte apunta que para el ejercicio de los derechos y garantías procesales por parte de los niños, dado la especial condición en que se encuentran, deben adoptarse "medidas específicas" que les permitan efectivamente el goce de tales derechos. ${ }^{28}$ Incluso añade, que se debe considerar la posibilidad y conveniencia de que las formas procesales revistan "modalidades propias" tratándose de niños (Berrios, 2012: 119). Ahora, como crítica Beloff (2007: 77-91), la Corte no indica cuales son estas "medidas específicas" o "modalidades propias", sin perjuicio de ello pareciera que se refieren a que hay una ritualidad (que no se agota en lo normativo) que necesariamente debe ser revisada. La especialidad procesal no es entonces empujar a los niños a los procedimientos de adultos, se trata de que los procesos de los adultos experimenten cambios dado la condición en que los niños se encuentran. Esto va en la línea de lo sostenido por Duce como segundo eje de manifestación del principio de especialidad, la "estructura general del procedimiento". Que se refiere a un conjunto misceláneo de elementos de diseño de un proceso, destinados a satisfacer objetivos específicos de la justicia penal juvenil (Beloff, 2007: 119), con la finalidad que hemos enunciado, fomentar y promover el ejercicio autónomo de los derechos por sus titulares.

\subsection{Síntesis}

Los dos grupos de problemas planteados en este capítulo, a nuestro entender, fijan un escenario distinto para la discusión sobre la procedencia del abreviado en el Proceso penal juvenil. Una forma de aproximación al problema que de especial relevancia a los derechos del niño, objetivo pretendido en este trabajo, debe necesariamente considerar como ejes de la discusión los problemas no zanjados sobre las competencias y capacidades de los adolescentes y el problema pendiente sobre el alcance de la especialidad del Proceso penal juvenil. De esta forma, el problema que nos convoca debiera tener un tratamiento más global desde el punto de vista del diseño del sistema penal juvenil. Es decir, se trata de que la forma más adecuada de resolver la procedencia del abreviado tratándose de adolescentes debiese en primer término hacerse cargo de las diversas interrogantes que los dos problemas aquí desarrollados puedan generar. Luego, en la medida que sistemáticamente concurran al diseño ambos aspectos es posible sostener que el

\footnotetext{
${ }^{27}$ Claramente excede los objetivos de este trabajo profundizar en las implicancias de la sintética conceptualización del principio de especialidad procesal penal juvenil que se ha efectuado, y del estándar propuesto para verificar su presencia, pero existen varios ámbitos -en lo procesal- que pudiesen ser objeto de una mayor indagación, por ejemplo: los sistemas de gestión de audiencias, la organización y gestión administrativa de los intervinientes institucionales en el sistema penal, la ritualidad del procedimiento, entre otros.

${ }^{28}$ Opinión Consultiva No 17 de 208 de agosto de 2002, p. 98.
} 
problema ha sido abordado adecuadamente y la decisión sobre aplicación del abreviado o no, se encuentra suficientemente justificada.

En nuestro escenario, a casi una década de vigencia de la LRPA, es difícil sostener que los problemas aquí desarrollados tuvieron un tratamiento adecuado tanto en el debate legislativo como en el resultado concreto que es el actual texto de la Ley 20.084. Sin dudas, en estos puntos la LRPA es deficitaria. La interrogante valida, es si por este hecho se debiese rechazar la procedencia del abreviado en los términos que se encuentra concebido en el CPP. Nuestra postura al respecto es que una dogmática que integre los derechos del niño al debate no debiese concluir algo distinto al rechazo del abreviado en su formulación actual. El diseño del sistema no cumple con dos grandes ámbitos que los principios y garantías desarrollados en el campo de los derechos de los niños exigen, esto es, abordar acertadamente los problemas de competencias y capacidades de los adolescentes para enfrentar a la justicia penal y configurar un proceso penal efectivamente especializado. Esto no obsta, por cierto, a emitir un pronunciamiento más específico en el campo en que actualmente la doctrina ha situado el problema, siempre bajo el prisma que aquí hemos dado. Este es el objetivo del capítulo siguiente.

\section{Procedencia e improcedencia del procedimiento abreviado, y bajo qué condiciones, en la justicia penal juvenil}

No obstante haber planteado que el debate sobre la procedencia del procedimiento abreviado debe responder en primer término preguntas más complejas desde el punto de vista del diseño del sistema penal juvenil, abordaremos ahora el escenario en que la escasa doctrina que se ha desarrollado al respecto fija el debate.

Estos aspectos son (i) los estándares de renuncia de derechos y (ii) el rol de los abogados defensores. Ambos suelen ser conceptualizados como garantías que operarían despejando cualquier duda que se tenga sobre si debiese aplicarse el abreviado a los adolescentes, de aquí la justificación de su tratamiento. Digamos, los argumentos esgrimidos podrían sintetizarse de la siguiente forma: a) el abreviado no presenta problema tratándose de adolescentes porque exigimos mayores estándares para la renuncia de derechos y este puede ser positivo para ellos, por ende la preocupación debe estar en la voluntariedad; y, b) si existe alguna duda respecto de que el abreviado pudiese no ser comprendido en su magnitud por el adolescente imputado, esto no sería problemático porque cuenta con un abogado defensor que además cumple el mandato de ser especializado. Analizaremos ambas posiciones.

\subsection{Estándares para la renuncia de derechos}

La doctrina nacional que se ha manifestado expresamente a favor de la procedencia del abreviado lo hace concibiendo el debate como un problema de 
exigencias para la renuncia de los derechos. ${ }^{29}$ En todo caso, siempre alerta de los riesgos que este tipo de mecanismos puede implicar para los adolescentes, con el foco en la voluntariedad.

A nuestro parecer, si la lógica detrás de aceptar esta institución en el ámbito penal juvenil es que el adolescente pueda encontrarse en una mejor posición de cara a sus intereses y, por lo mismo, debiésemos proteger especialmente su voluntariedad, entonces el procedimiento abreviado tal y como está regulado en el CPP no debiese ser aplicable a los adolescentes, toda vez que de la revisión de sus requisitos de procedencia no puede colegirse tal protección. Veamos esto en detalle.

El artículo 406 del CPP, luego de indicar el marco penológico que permite sustituir el procedimiento ordinario por el procedimiento abreviado, establece en su inciso segundo cuatro aspectos o requisitos que sumados al marco penológico permiten la aplicación del procedimiento. Estos implican que el imputado deberá:

1. Tener conocimiento de los hechos materia de la acusación.

2. Tener conocimiento de los antecedentes de la investigación.

3. Aceptar expresamente los antecedentes de la investigación (vinculado a los hechos que la sostienen).

4. Manifestar su conformidad con la aplicación del procedimiento.

Si se aprecian los estándares exigidos por el CPP para proceder conforme al abreviado, vemos que estos aluden a competencias y capacidades que son inferiores a aquellas competencias y capacidades "primarias" o "mínimas" -antes expuestasque debe tener cualquier imputado para siquiera "ayudar a su abogado defensor" y poder, de esta forma, participar en su propia defensa en el proceso penal.

En los dos primeros requisitos el legislador estableció estándares que desde el punto de vista de la mayoría de las clasificaciones vinculadas a la teoría del conocimiento se encuentran en lo más bajo. Tener conocimiento de los hechos materia de la acusación como de sus antecedentes no excede el pensamiento memorístico. Las capacidades y competencias mínimas de un imputado propuestas por Bonnie y Grisso (2000: 76) se encuentran un peldaño más arriba que el CPP. Requieren de cierto procesamiento del pensamiento que se tiene, por esta razón se plantea que el imputado debe "comprender" los cargos y el sistema de enjuiciamiento, asimismo debe poder "apreciar" la situación concreta en que se encuentra y ser capaz de "relacionar" los antecedentes con los hechos que se le imputan con la finalidad de poder ayudar a su abogado a cumplir su rol técnico.

\footnotetext{
${ }^{29}$ En este sentido, Véase: Duce (2013a: 79). El autor es de la idea de que la posibilidad debe existir, especialmente cuando la renuncia les puede permitir obtener una mejor posición para satisfacer sus intereses. En igual sentido Marín Verdugo, citado en: Duce (2013b: 264), quien sería de la idea de permitir el abreviado pero con mayores exigencias para el juez al momento de verificar la voluntariedad del adolescente debido al estado de desarrollo de su autonomía.
} 
Dicho de otra forma, el estándar exigido por el CPP (en los puntos 1 y 2) no es más que evitar la "ignorancia" del imputado. Claramente, el asunto no se trata de que sin el conocimiento del imputado no pueda haber procedimiento abreviado, sino que sin conocimiento del imputado no puede existir ningún tipo de procedimiento. Digamos los estándares contenidos en 1 y 2 no aportan nada nuevo -no mejoran- a los estándares igualmente presentes como garantías de debido proceso en el procedimiento ordinario. Y pareciera ser que, tratándose de un procedimiento donde se está planteando la renuncia al derecho a un juicio oral y acercándose a una declaración de culpabilidad, estos estándares deberían ser más elevados (a nivel de adultos, sin entrar a las particularidades de los adolescentes).

Luego, exigir la aceptación -por mucho que sea expresa- de los antecedentes que sostienen la investigación fiscal y manifestar su conformidad para que se aplique el procedimiento abreviado, se torna un tanto ilusorio. Desde el "saber" (o tener conocimiento) que algo existe al "manifestar su conformidad" a ello, hay un trecho mucho más extenso que recorrer, que está dado principalmente por una serie de otras capacidades y competencias cognitivas que deben estar presentes en el imputado para que la ritualidad exigida por el proceso no sea finalmente mera apariencia y/o arbitrariedad. En específico, hablamos de aquellas "competencias decisionales" antes mencionadas, que presentan un estadio superior en el campo de los niveles del conocimiento (por ej., pensamiento estratégico y pensamiento extendido).

Exigir la toma de decisiones que requieren importantes competencias y capacidades por parte de los imputados, conformándose únicamente con verificar niveles inferiores a aquellas mínimas competencias y capacidades para poder "ayudar al abogado defensor" convierte a las garantías en una mera declaración de buenas intenciones. Toda vez que, finalmente lo que debe verificar el juez de garantía para la procedencia del abreviado es bastante poco, el ámbito de protección al imputado en este contexto específico es bastante mínimo y cede desproporcionadamente a favor de la eficiencia del sistema. ${ }^{30}$ Aun cuando no es el foco de este trabajo, esto además debe apreciarse considerando quienes son los sujetos "clientes" del sistema penal. En síntesis, por una parte, tenemos estándares normativos bastante bajos en relación a las competencias y capacidades que exigimos de los imputados para aplicar el procedimiento abreviado y, por otra, sabemos que los sujetos que mayoritariamente son objeto de persecución penal han estado fuera de las políticas sociales que pudiesen haber influido en el desarrollo de las competencias y capacidades necesarias para enfrentar el proceso penal.

En el seno de los problemas ya desarrollados veamos la situación de los adolescentes. En referencia a los hallazgos de Buss (2000: 244), además de los problemas presentes a nivel general en el Proceso penal respecto de las

\footnotetext{
${ }^{30}$ Nos parece que el punto aquí aludido sin duda ha influido en el funcionamiento del sistema penal. Elevadas cifras de utilización del abreviado algún grado de relación tienen con los escasos elementos que debe apreciar el juez de garantía para dar su conformidad a la aplicación del mismo.
} 
competencias y capacidades que se exigen de una persona para ser juzgada, dijimos que los adolescentes se quedan más atrás en tres ámbitos específicos: su capacidad para comprender sus derechos; su capacidad de comprender el proceso de juzgamiento (incluido el rol de su abogado en el proceso); y, su capacidad de tomar decisiones que sirvan a sus propios intereses (especialmente aquellos de largo plazo). Es decir, se trata tanto de competencias mínimas que deben estar presentes para "ayudar al abogado" o participar en su propia defensa, como de "competencias decisionales". Todas involucradas por cierto, en las implicancias del procedimiento abreviado (aun cuando no lo haya estimado así el legislador).

Planteado así el conflicto, mayores exigencias para la renuncia de derechos por parte de los adolescentes no resuelven los problemas de déficit de capacidades y competencias que suelen tener los adolescentes al enfrentar el Proceso penal. Aún si el esfuerzo por verificar las condiciones establecidas en el art. 406 del CPP por parte del juez de garantía fuera más intenso, dada la forma en que se concibieron los estándares no es mucho más lo que va a poder verificar. Porque no se trata de quedar sin dudas sobre si el adolescente conoce los hechos y los antecedentes de la investigación y que consienta de manera expresa en continuar conforme al procedimiento abreviado, sino que de indagar en aquellas otras competencias y capacidades requeridas para enfrentar una problemática decisional como la que implica el abreviado. ${ }^{31}$

Respecto del tema de los intereses -esta postura sostiene que el abreviado pudiese ser lo mejor para los intereses del adolescente en casos determinados-, nuestro abreviado como ha diagnosticado la doctrina, deja en el ámbito de lo informal la negociación de penas. ${ }^{32}$ Esto complejiza aún más el asunto, dado que el diseño normativo no impide que los adolescentes puedan verse envueltos en una serie de presiones para renunciar a su posibilidad de controvertir los cargos. En este escenario, el tema de las competencias y capacidades cobra plena relevancia. Este tipo de decisiones, que puedan servir a sus propios intereses (de largo plazo), son de aquellas que requieren un desarrollo elevado de competencias y capacidades en los adolescentes. Y donde la escasa información empírica existente dice que no las tienen desarrolladas. Ya es dificultosa para los adolescentes la comprensión de sus propios derechos para exigir además que puedan negociar con ellos. No se trata de asumir una concepción tutelar, por el contrario, se trata de asumir una concepción que pregone el ejercicio de los derechos por parte de los adolescentes (con las serias dificultades que esto de por sí ya importa). A esto se puede añadir que el artículo 406 del CPP en ninguno de sus requisitos abre alguna puerta que le permita al juez de garantía indagar la existencia de una voluntad real emanada del ejercicio de competencias decisionales.

\footnotetext{
${ }^{31}$ Inclusive pudiese ser cuestionable desde el punto de vista de las fuentes legales (en sentido amplio) la existencia de una obligación para el juez de garantía de indagar de manera más intensa la concurrencia de los requisitos en razón de la calidad de adolescentes, aun cuando esto pudiese parecer deseable.

${ }^{32}$ La jurisprudencia citada por la doctrina denota claramente la existencia de este espacio informal.
} 
En gran medida el problema de situar el debate en el campo de exigencia de mayores estándares para la renuncia de derechos, es que trata de emplear estándares que son propios del sistema de adultos. Justamente una de las mayores críticas que se ha formulado a la doctrina Miranda sobre renuncia de derechos en el ámbito de la justicia juvenil en Estados Unidos, ${ }^{33}$ es la aplicación de los estándares contenidos en esta doctrina de manera no diferenciada o "especializada" a los adolescentes. Dejándolos en peor situación que los adultos. La falta de adecuar estos estándares a las particularidades que presentan los adolescentes ha convertido estas garantías (exigidas para la renuncia) en ineficientes respecto de ellos (Feld, 2000). Es decir, se trata de que sin real certeza que los adolescentes cuenten con las competencias y capacidades -en cualquier caso- para renunciar a sus derechos, el estándar de los adultos ("verificar" la voluntariedad de la decisión) deja inoperante esta garantía respecto de los adolescentes. A nuestro parecer, el mismo problema estaríamos importando aun cuando exijamos mayor intensidad en la labor del juez de garantía para corroborar la voluntariedad contenida en el artículo 406 del CPP, porque el problema no es de verificación, sino que de competencias y capacidades de los adolescentes. No se puede verificar lo que no existe.

\subsection{El rol de los abogados defensores}

Independiente, e inclusive complementaria de la postura que ve en una mayor exigencia para la renuncia de derechos una garantía para la procedencia del abreviado en el ámbito penal juvenil, se encuentra la relativa al rol de los defensores. En síntesis, esta postura sostiene que los problemas que pueda presentar el abreviado en el caso de los adolescentes pueden ser superados por la vía de contar con abogados defensores, quienes además en el ámbito penal juvenil se encontrarían especializados.

Qué duda cabe que el derecho a defensa tiene una importancia vital en el procedimiento. Además, de ser una garantía integrante del debido proceso tiene la particularidad de que torna operativa las demás garantías que este contempla. ${ }^{34} \mathrm{En}$ este sentido, la postura aludida, apunta a un aspecto que no admite mayor discusión, la importancia de la defensa letrada. Sin embargo, el problema pasa por cuál es el propósito de la defensa técnica en el caso de los adolescentes.

\footnotetext{
${ }^{33}$ Como consecuencia del caso In re Gault, se hicieron aplicable a los adolescentes una serie de otros derechos y estándares contenidos en otras sentencias de la Corte Suprema Estadounidense, entre ellos la doctrina Miranda. Esta doctrina establece los estándares para renunciar a contar con la presencia de un abogado y declarar ante las policías en las primeras diligencias de investigación. Derecho a defensa técnica y derecho a guardar silencio. Advertencia que debe formularse a las personas que detenten la calidad de imputado. Los estándares se resumen en la siguiente frase, la renuncia debe darse "knowing, intelligent, and voluntary under the totally of the circumstances".

${ }^{34}$ En este sentido Cillero respecto de la diferencia entre defensa material y técnica, empleando el concepto de Riego, Véase: Cillero (2009: 12).
} 
Como señalamos antes, parece ser que la defensa técnica no puede completar los vacíos (que se producen por déficit en las capacidades o competencias) de la defensa material. Dicho de otra forma, la defensa técnica es una garantía para el cumplimiento efectivo de la defensa material (Cillero, 2009: 12). Si esto es así, entonces nuevamente volvemos al tema de las capacidades y competencias de los adolescentes.

Asumidos los déficit que presentan los adolescentes en este punto, Buss plantea precisamente que el rol de los abogados que representan a niños en procesos judiciales es promover, o tratar de mejorar, las competencias de sus clientes de cara al juicio, permitiéndoles de esta forma una mayor intervención y espacio para el ejercicio de sus derechos. ${ }^{35} \mathrm{La}$ pregunta que surge, asumido este objetivo extra para la defensa penal de adolescentes, es ¿puede lograrse este objetivo tratándose de todo tipo de déficit de capacidades y competencias? ¿Puede lograrse tratándose de aquellas competencias y capacidades más complejas que debe desarrollar un sujeto y que por lo demás son altamente personalísimas? Y la respuesta es que bajo ningún modelo, en lo que a relación abogado defensoradolescentes se refiere, es posible de ser logrado. Siempre existe un ámbito de limitaciones cognoscitivas y psicosociales (déficit de competencias y capacidades) que no podrán ser corregidas por el abogado defensor. ${ }^{36}$ Inclusive, puede ser que el adolescente cuente con altos niveles de desarrollo de sus capacidades y competencias pero aun así puede presentar limitaciones para participar efectivamente en su relación con el abogado defensor (Henning, 2005: 71). En todos estos casos, por muy especializada que sea la defensa penal con la que se cuente, es altamente improbable que esta pueda llegar a fomentar capacidades que simplemente aún no han sido adquiridas o desarrolladas por el adolescente.

Por ende, tampoco puede sostenerse prima facie, que la presencia de un defensor por muy especializado que sea, es garantía suficiente de que el sujeto que representa se encuentra efectivamente en condiciones de realizar una renuncia a sus derechos como resultado del ejercicio de sus competencias y capacidades.

Lo anterior, incluso ha sido expresamente recogido por la Corte Europea de Derechos Humanos. En el caso de V contra el Reino Unido, ${ }^{37}$ revisándose el caso de un niño de 11 años ("V") imputado de cometer dos delitos violentos, la Corte no consideró suficiente que el niño durante el proceso penal estuviese representado por abogados especialistas y experimentados, dado que producto de una serie de elementos que se dieron por establecidos ante la Corte (inhibición, temor, entre otros), el niño era inmaduro y se encontraba perturbado emocionalmente durante el proceso, por ende, era incapaz de cooperar con sus abogados y entregar información suficiente para su propia defensa. Por este

\footnotetext{
35 Buss (2000: 253-263). En igual sentido, Véase: Cillero (2009: 21-37).

36 Una reflexión sobre este punto puede encontrarse en: Henning (2005: 70-123).

${ }^{37}$ European Court of Human Rights: "Case of V. v. The United Kingdom, de 16 de diciembre de 1999, especialmente párrafos $\mathrm{N}^{\circ}$ s 81-91.
} 
motivo, la Corte concluye que el niño era incapaz de participar efectivamente en el proceso criminal que se seguía en su contra. ${ }^{38}$

De este modo, como señalábamos, ni aún la más especializada y experimentada de las defensas puede suplir la carencia de las capacidades y competencias necesarias, en sus distintos niveles, para que un adolescente pueda ser enjuiciado, so pena de estimar como nulas (en sentido amplio) las actuaciones que se desarrollen en el marco del proceso.

\subsection{Necesidad de reforma legal. Aspectos generales}

Como hemos señalado, el abreviado en los términos en que se encuentra regulado en el CPP no debiese aplicarse a los adolescentes ni por razones de diseño del sistema penal juvenil (que involucra los problemas de competencias y capacidades de los adolescentes y las diferencias que el proceso penal juvenil debe tener respecto de los adultos), ni por los argumentos que ha dado la doctrina en el escenario que ha fijado para el debate. Es decir, sin reforma legal no debiese ser aplicable el abreviado a los adolescentes. Y si tal fuera la intención, nos parece que a lo menos la reforma legal debiese tener en consideración los siguientes aspectos.

Sin plantear tramos etarios, el pensar en una renuncia de derechos efectiva -es decir, que sea fruto de una decisión autónoma (en sujetos con déficit de autonomía), que requiere además una serie de competencias y capacidades asociadas para verificarse voluntariamente-, parece sumamente complejo de hallar en edades más próximas a la inimputabilidad (a nivel general y no en relación a adolescentes en concreto). El punto no es negar que producto de un procedimiento abreviado en determinados casos los adolescentes puedan obtener una "mejor" sanción, lo que podría ser adecuado para sus intereses, sino que el punto consiste en que el sistema efectivamente esté diseñado para que eso pueda ocurrir y, más aún, si esto puede ocurrir tratándose de todo tipo de adolescentes.

En el contexto anterior, a nuestro parecer el abreviado aún con modificaciones no podría aplicarse a todos los adolescentes, no al menos a los más cercanos a la edad de inimputabilidad. Existen demasiados conflictos para sostener

\footnotetext{
38 90. In such circumstances the Court does not consider that it was sufficient for the purposes of Article $6 \int 1$ that the applicant was represented by skilled and experienced lawyers. This case is different from that of Stanford (cited in paragraph 82 above), where the Court found no violation arising from the fact that the accused could not hear some of the evidence given at trial, in view of the fact that his counsel, who could hear all that was said and was able to take his client's instructions at all times, chose for tactical reasons not to request that the accused be seated closer to the witnesses. Here, although the applicant's legal representatives were seated, as the Government put it, "within whispering distance", it is highly unlikely that the applicant would have felt sufficiently uninbibited, in the tense courtroom and under public scrutiny, to have consulted with them during the trial or, indeed, that, given his immaturity and his disturbed emotional state, he would have been capable outside the courtroom of cooperating with bis lanyers and giving them information for the purposes of his defence.

91. In conclusion, the Court considers that the applicant was unable to participate effectively in the criminal proceedings against him and was, in consequence, denied a fair hearing in breach of Article $6 \int 1$.
} 
que una renuncia en aquellos casos sea realmente legítima (fruto del ejercicio de un conjunto de capacidades y competencias de diversos niveles que exige el proceso penal). En el caso de estos adolescentes lo más adecuado sería establecer un juicio efectivamente simplificado en razón de sus reales posibilidades de participación en el mismo.

Mientras que respecto de adolescentes cercanos a la mayoría de edad (inclusive aquellos que ya son mayores de edad y están amparados por la LRPA por la fecha de comisión del delito), en la medida en que puedan verificarse de alguna forma (inclusive a través de otro tipo de asistencia adecuada, conforme al artículo 37 d) de la $\mathrm{CDN}$ ) la presencia de las competencias y capacidades requeridas para comprender cabalmente en qué consiste la renuncia y las consecuencias de ello, no sólo la voluntariedad de la decisión, sumado a la supresión de la negociación de penas, podría permitirse el abreviado en determinados casos.

La justificación del abreviado, en este esquema, no radica en un posible premio por evitarle gastos al Estado, sino que tiene su fundamento en que bajo determinadas circunstancias, bajo el riesgo de la misma pena -sin rebaja- (Beloff et al, 2015: 28), se prefiera no enfrentar el juicio oral. Decisiones principalmente vinculadas al desarrollo de los adolescentes, donde enfrentar el juicio pueda ser un elemento negativo, teniendo las capacidades y competencias para enfrentarlo ${ }^{39}$. Razones que puedan involucrar la realización de otros derechos, por ejemplo la privacidad. Que como toda decisión que implica niveles de ponderación entre algún o algunos derechos y otro u otros, requiere de altos niveles de desarrollo de competencias y capacidades individuales para construir una posición al respecto.

En síntesis, la orientación sería a: i) establecer respecto de las edades más próximas a la inimputabilidad un procedimiento efectivamente simplificado, pero no en la lógica del regulado en el CPP, sino en base al segundo eje sostenido por DUCE, una estructura de procedimiento ad hoc a las capacidades y competencias que en ese rango de edad, conforme a la evidencia, efectivamente estén presentes en los adolescentes y permitan el ejercicio autónomo de los derechos, todo esto bajo la cláusula de no suprimir la idea misma de proceso; y, ii) permitir una forma de procedimiento abreviado que no se movilice por la lógica de negociación en virtud de rebaja de penas y donde efectivamente el juez de garantía tenga las herramientas necesarias para acreditar que la decisión que manifieste el adolescente es fruto de las competencias y capacidades que una decisión de este tipo involucra.

\footnotetext{
${ }^{39}$ Este aspecto es relevante, el abreviado y mecanismos similares pueden fácilmente ser empleados para no evidenciar la falta de capacidades y competencias que tendría un adolescente en el juicio oral.
} 


\section{Reflexiones finales}

El problema de la procedencia del procedimiento abreviado en la justicia penal juvenil tiene una dimensión más profunda y compleja, que está dada por los grandes desafíos que plantea el enfoque de derechos del niño a nivel dogmático. Por una parte, incorporar los problemas de las competencias y las capacidades de los adolescentes y, por otra, tomarse en serio el desafío de configurar un Proceso penal que sea realmente especializado. Abordar el debate como uno vinculado a mayores exigencias para la renuncia de derechos, si bien lo extrae del ámbito formal (centrado en si acaso la ausencia de referencia en la LRPA al procedimiento abreviado tiene un significado concreto a favor o en contra de la institución), no resuelve el problema.

Es necesario no subsumir bajo la idea de imputabilidad el conjunto de competencias y capacidades que el Proceso penal exige de parte de los adolescentes. Se debe profundizar en las características que presentan los adolescentes para delinear de manera efectiva como debiese ser el proceso de imputación penal. La escasa evidencia existente al respecto muestra que el sistema se conforma con una ficción acerca de las capacidades y competencias de los adolescentes. Todo esto nos retrotrae peligrosamente a los sistemas que se decidió sustituir. En este contexto, la defensa técnica nunca puede ser empleada como pretexto para justificar la procedencia de actuaciones procesales o validar algunas de ellas respecto de adolescentes que no tengan las competencias y capacidades que estas requieren.

El procedimiento abreviado, tal y como está concebido, no debiese ser aplicado a los adolescentes. Toda vez que sus requisitos de procedencia no permiten verificar efectivamente aquellos déficits que presentan los adolescentes en los procesos penales, especialmente en lo que se refiere a la autonomía, objetivo del principio de especialidad. Sería deseable efectuar una distinción entre aquellos adolescentes más próximos a la edad de inimputabilidad, respecto de quienes no se debiese contemplar el abreviado, y entre aquellos más próximos a la mayoría de edad, quienes en la medida en que no exista negociación de penas y se empleen mecanismos para verificar que cuentan con las competencias y capacidades necesarias para renunciar a sus derechos, puedan acceder al abreviado bajo determinados supuestos. Lo anterior, no es posible de concretar sin previa modificación legal. 
Leiva - La especialidad del proceso penal juvenil y el procedimiento abreviado

\section{BIBLIOGRAFÍA}

* ALÁEZ, Benito (2007): "El ejercicio de los derechos fundamentales por el menor de edad", en: Revista del Instituto de Ciencias Jurídicas de Puebla A.C., No 20, pp.179-210.

* Beloff, Mary (2007): "Luces y sombras de la opinión consultiva 17 de la Corte Interamericana de Derechos Humanos: "Condición jurídica y derechos humanos del niño", en: Revista Justicia y Derechos del Niño No 9, Unicef, pp. 49-123.

* Beloff, Mary; Freedman, Diego; Kierszenbaum, Mariano y Terragni, Martiniano (2015): "La justicia juvenil y el juicio abreviado", en La Ley, año LXXIX N 73, pp. 1-8.

* Berrios, Gonzalo (2012): "Los adolescentes mapuche y las reformas a la Ley No. 18.314 sobre conductas terroristas", en: Anuario de Derechos Humanos 2012, Universidad de Chile, Santiago, pp. 147-154.

* Berrios, Gonzalo y Vial, Luis (2011): Tres años de vigencia: Ley de responsabilidad penal adolescente, Defensoría Penal Pública, Santiago, 44 pp.

* BONNIE, Richard y GRISSO, Thomas (2000): "Adjudicative competence and youthful offenders", en: Grisso, Thomas y Schwartz, Robert (Ed.): Youth on Trial: A developmental perspective on Juvenile Justice, University of Chicago Press, Chicago, pp. 73-103.

* Buss, Emily (2000): "The role of lawyers in promoting juveniles' competence as defendants", en: Grisso, Thomas y Schwartz, Robert (Ed.): Youth on Trial: A developmental perspective on Jwvenile Justice, University of Chicago Press, Chicago, pp. 243-265.

* Cillero, Miguel (2003): "De la tutela a las garantías: consideraciones sobre el proceso penal y la justicia de adolescentes", en: Revista de Derechos del Niño No 2. Unicef, pp. 53-86.

(2005): "La responsabilidad penal de adolescentes y el interés superior del niño", en: Revista Justicia y Derechos del Niño No 7, Unicef, pp. 97-103.

(2009): "El derecho a la defensa penal de adolescentes", en: Informes en Derecho: Estudios de Derecho penal Juvenil I, Defensoría Penal Pública, No 5, pp. 9-45.

* Couso, Jaime (2007): "Principio educativo y (re)socialización en el Derecho penal juvenil", en: Revista Justicia y Derechos del Niño No 9, Unicef, pp. 219-231.

(2013): "Fundamentos empíricos y normativos del mandato de especialidad en el derecho penal y procesal penal de adolescentes", en: Couso, Jaime y Duce, Mauricio: Juzgamiento Penal de Adolescentes, Ediciones LOM, Santiago, pp. 21-41.

* De Ferari, Ignacio (2006): "Quince años de espera... Hacia la creación de un sistema de reemplazo: Notas sobre la génesis y desarrollo de la Ley sobre Responsabilidad Penal Adolescente", en: Revista Justicia y Derechos del Niño No 8, Unicef, pp. 113-158.

* Del Río, Carlos (2008): "El principio de consenso de las partes en el proceso penal y enjuiciamiento jurisdiccional: aclaraciones conceptuales necesarias", en: Revista Chilena de Derecho, vol. $35 \mathrm{~N}^{\circ}$ 1, pp. 157-182.

* DíAz, Fernando (2001): "Juicio abreviado vs. Estado de Derecho", en: Maier, Julio y Bovino, Alberto (comps.), El procedimiento abreviado, Editores del Puerto, Buenos Aires, pp. 251-276.

* Duce, Mauricio (2003): "El proceso establecido en el proyecto de ley que crea un Sistema de Responsabilidad de los Adolescentes por infracciones a la Ley Penal: Avances y Problemas", en: Revista de Derechos del Niño No 2, Unicef, pp. 99-113.

(2013a): "El derecho a un juzgamiento especializado de los jóvenes infractores en el derecho internacional de los derechos humanos y su impacto en el diseño del proceso penal juvenil", en: Couso, Jaime y Duce, Mauricio: Juzgamiento Penal de Adolescentes, Ediciones LOM, Santiago, pp. 43-105.

(2013b): "El derecho a un juzgamiento especializado de los jóvenes infractores en el nuevo proceso penal chileno", en: Couso, Jaime y Duce, Mauricio: Juzgamiento Penal de Adolescentes, Ediciones LOM, Santiago, pp. 201-299.

* Duce, Mauricio y Riego, Cristián (2007): Proceso Penal, Editorial Jurídica de Chile, Santiago, 583 pp.

* FELD, Barry (2000): “Confessions, Miranda, and the right to a counsel”, en: Grisso, Thomas y Schwartz, Robert (Ed.): Youth on Trial: A developmental perspective on Juvenile Justice, University of Chicago Press, Chicago, pp. 105-138. 
* Ferrajoli, Luigi (2001): "Las lesiones al modelo constitucional del proceso penal”, en: Maier, Julio y Bovino, Alberto (comps.): El procedimiento abreviado, Editores del Puerto, Buenos Aires, pp. 31-50.

(2004), Derecho y razón, Trotta, Madrid, 1019 pp.

* Garrido, Ricardo (2011): "Derecho a un juzgamiento especializado de niños, niñas y adolescentes y teoría general del proceso", en: Revista Pensamiento y Poder, vol. 1 No 7, pp. 7-28.

* Grisso, Thomas (2000a): “Adolescents' capacities as trial defendants. Introduction", en: Grisso, Thomas y Schwartz, Robert (Ed.): Youth on Trial: A developmental perspective on Juvenile Justice, University of Chicago Press, Chicago, pp. 67-71.

(2000b): "What we know about youths' capacities as trial defendants", en: Grisso, Thomas y Schwartz, Robert (Ed.): Youth on Trial: A developmental perspective on Juvenile Justice, University of Chicago Press, Chicago, pp. 139-171.

* HenNing, Kristin (2005): "Lealtad, paternalismo y derechos: teoría sobre el asesoramiento al cliente y rol del abogado del niño en casos de delincuencia", en: Informes en Derecho: Estudios de Derecho penal Juvenil II, Defensoría Penal Pública, pp. 45-124.

* Historia de la Ley No 20.084 (2005): Establece un sistema de responsabilidad de los adolescentes por infracciones a la ley penal. 07 de diciembre, 2005. Biblioteca del Congreso Nacional de Chile. Disponible en http://www.bcn.cl/historiadelaley/nc/historia-de-laley $/ 5762 /$.

* Langbein, John (2001): “Tortura y plea bargaining”, en: Maier, Julio y Bovino, Alberto (comps.): El procedimiento abreviado, Editores del Puerto, Buenos Aires, pp. 3-29.

* Langer, Máximo (2001): "La dicotomía acusatorio-inquisitivo y la importación de mecanismos procesales de la tradición jurídica anglosajona. Algunas reflexiones a partir del procedimiento abreviado", en: Maier, Julio y Bovino, Alberto (comps.): El procedimiento abreviado, Editores del Puerto, Buenos Aires, pp. 97-133.

(2004): "From legal transplants to legal translations: The globalization of plea bargaining and the americanization thesis in criminal procedure", en: Public Law \& Legal Theory Research Paper Series, Research Paper No 05-10, University of California, Los Angeles, pp. 1-65.

(2007): Revolución en el proceso penal latinoamericano: difusión de ideas legales desde la periferia, Centro de Estudios de las Américas. Diponible en: http://www.cejamericas.org

* Maldonado, Francisco (2010): "Responsabilidad penal juvenil: Estado actual y perspectivas", en: Revista General de Derecho Penal, Iustel No 14, pp. 1-33.

(2014): "Consideraciones acerca del contenido de la especialidad que caracteriza a los sistemas penales de adolescentes", en: Revista de Derecho - Escuela de Posgrado, Facultad de Derecho, Universidad de Chile $\mathrm{N}^{\circ}$ 5, pp. 17-54.

* Riego, Cristián (2001): "El procedimiento abreviado en Chile", en: Maier, Julio y Bovino, Alberto (comps.): El procedimiento abreviado, Editores del Puerto, Buenos Aires, pp. 453-475.

* Rodríguez, Manuel (2011): "Discrecionalidad del Ministerio Público y el objeto del juicio abreviado", en: Revista de Derecho, Pontificia Universidad Católica de Valparaíso XXXVI pp. 495-529.

* SAla, Cristina (2002): Proceso penal de menores: especialidades derivadas del interés de los menores y opciones de política criminal, tesis doctoral, $461 \mathrm{pp}$. Disponible en: http://m.dugidoc.udg.edu/bitstream/handle/10256/4794/tcsd.pdf?sequence=1 (fecha de consulta: $10 \mathrm{de}$ septiembre de 2015). 